\title{
A Model of Coupled Heat and Moisture Transport in an Annular Clay Barrier
}

\author{
L. Rossi* \\ H. I. Inyang ${ }^{\dagger}$ \\ J. Graham-Eagle \\ S. Pennell ${ }^{\S}$
}

Technical Report No. 2002-15

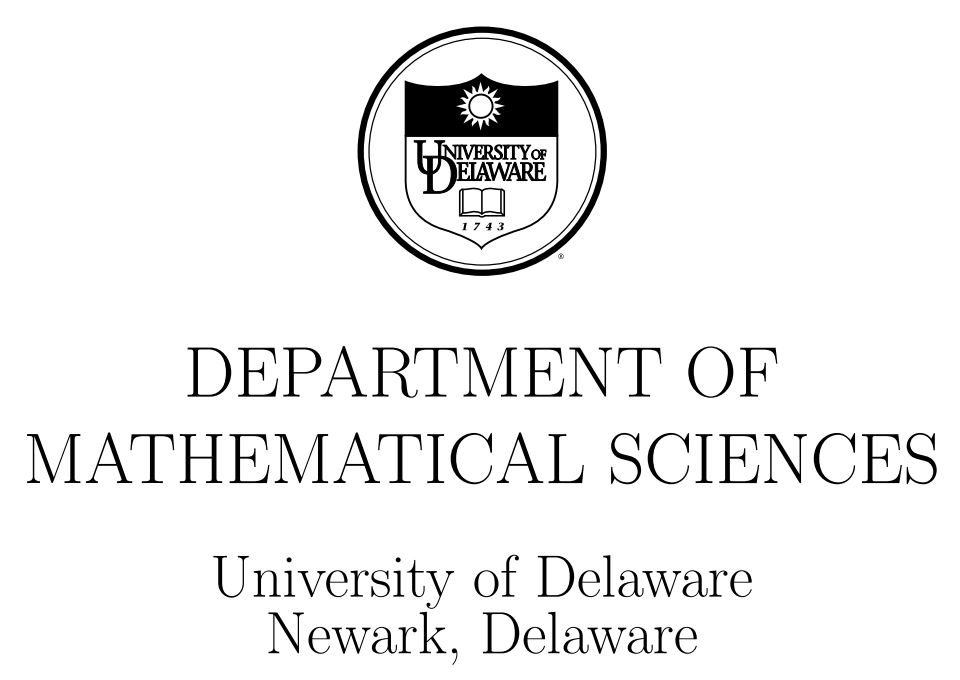

*Associate Professor, Department of Mathematical Sciences, University of Delaware, Newark, DE 19716-2553

${ }^{\dagger}$ Duke Energy Distinguished Professor and Director, Global Institute for Energy and Environmental Systems (GIEES), University of North Carolina at Charlotte c/o C. C. Cameron Research Center, Room 2389201 University City Blvd., Charlotte, NC 28223-0001

${ }_{\ddagger}^{\ddagger}$ Associate Professor, Department of Mathematical Sciences, University of Massachusetts Lowell, Lowell, MA 01854

${ }^{\S}$ Professor, Department of Mathematical Sciences, University of Massachusetts Lowell, Lowell, MA 01854 


\title{
A Model of Coupled Heat and Moisture Transport in an Annular Clay Barrier
}

\author{
L. Rossi ${ }^{1}$, H. I. Inyang ${ }^{2}$, J. Graham-Eagle ${ }^{3}$, and S. Pennell ${ }^{4}$
}

Abstract. The design of repository seals for deeply buried high-level radioactive wastes incorporates densely compacted clayey barriers around metallic waste canisters. In this paper, a mathematical model that is based on conservation of thermal energy and mass is developed to describe the locations of moisture and temperature fronts within a barrier, around a cylindrical waste canister of 1-meter radius, containing radionuclides with half-lives that range from $100-$ 10,000 years. The solution developed is axisymmetric: the moisture fraction, $w$, and temperature $\mathrm{T}$, vary only with time $t$, and radial distance $r$ from the axis of the cylindrical waste canister. The model produces parabolic partial differential equations (PDEs). The spatial domain is discretized such that ordinary differential equations (ODEs) that result are solved. Computations using a uniform mesh of 0.1 meters and a cooling coefficient of $6.7 \times 10^{-2}$ with assumed but typical data on material properties, indicate that coupling of transport processes would be negligible in the case of radionuclides with long half-lives. Also, a quasi-steady vaporization front can form and propagate outward over the course of several decades after waste emplacement. The evolution of the front is somewhat insensitive to the half-life used and the permeability of the clayey barrier material.

\footnotetext{
${ }^{1}$ Associate Professor, Department of Mathematical Sciences, University of Delaware, Newark, DE 19716-2553

2 Duke Energy Distinguished Professor and Director, Global Institute for Energy and Environmental Systems (GIEES), University of North Carolina at Charlotte c/o C. C. Cameron Research Center, Room 238, 9201 University City Blvd., Charlotte, NC 28223-0001

${ }^{3}$ Associate Professor, Department of Mathematical Sciences, University of Massachusetts Lowell, Lowell, MA 01854

${ }^{4}$ Professor, Department of Mathematical Sciences, University of Massachusetts Lowell, Lowell, MA 01854
}

Key words: radioactive waste, barrier material, waste containment, coupled transport, illitization 


\section{INTRODUCTION}

Some plans for long-term storage of high-level nuclear waste involve the burial of waste canisters within engineered clay barriers in geologically stable areas. The principal concerns with this storage plan are the potential for leaching of radionuclides into the surrounding groundwater and the associated risk of ecological and human exposure. Clay barriers can be altered by a variety of complex chemical processes, including dehydration, infiltration of moisture and electrolytes, radiation damage, dissolution and leaching, precipitation, and illitization. To simulate these barrier degradation processes over long periods of time, it is crucial to be able to describe the fluid transport processes that deliver moisture and the substances that it may contain to reaction sites in the barrier. A fundamental requirement for estimation of the rate of mineralogical changes in the barrier material during the service life of the repository is knowledge of the temperature and moisture content and gradient between the canister and the host rock. When the waste canister is first set in place, heat from the waste material causes a vaporization front to develop and move outward from the canister through the barrier, toward the host rock. As the waste decays and its heat output decreases, the vaporization front moves slowly back toward the canister. This paper focuses on the development of a model to describe the evolution of the vaporization front for use in calculating the temperature and moisture content of various regions of the barrier.

This paper is organized as follows. The significance of the transport processes that can alter the barrier over long periods of time is described in section 2. A mathematical model of the evolution and transport of thermal energy and moisture in the porous matrix surrounding the waste canister is developed in section 3. This coupled system of partial differential equations is adapted to a cylindrical geometry to quickly capture the essential configuration and coupled 
heat/mass transport pattern of the barrier. Section 4 covers the implementation of a simple method-of-lines scheme to solve the system of partial differential equations in the cylindrical geometry. Sample computations of the advance of the vaporization front in an axisymmetric domain are presented in section 5 .

\section{RELATIONSHIP OF TRANSPORT PROCESSES TO BARRIER DETERIORATION AND CONTAMINANT RELEASE}

Establishment of hydraulic linkage between radionuclides contained in canisters and groundwater in the host rock is controlled by barrier alteration processes and the extent to which fluids can travel through the barrier. Barrier alteration and fluid flow processes in near-surface environments that are characterized by low confining pressures and alternating heat and moisture conditions have been described by several investigators among whom are Daniels et al. (2000), Daniels and Inyang (2002), Chen et al. (2000), Shi et al. (1999), Inyang et al. (1997), Bai et al. (1997), and Inyang et al. (2000).

In the deep sub-surface environment in which pressures are very high and temperature differential between the waste canister and the host rock can reach $150{ }^{\circ} \mathrm{C}$, coupled mass and heat transport will occur. Unlike the case of near-surface environments where barrier damage is mostly caused by alternating conditions such as wet-dry cycling, diurnal heating and the movement of mineralized water that is typical of the deep subsurface, into the emplaced barrier can induce fluid-barrier mineral reactions that alter the mineralogy of the barrier layer. Indeed, mineralogical changes imply changes in the magnitude of barrier textural parameters such as radionuclide diffusion coefficient and permeability that may be significant with respect to the 
long-term release of radionuclides in the host rock and subsequent migration into the nearsurface environment. Earlier research has focused on characterization of the textural and hydraulic aspects of rocks that could impact the transport rates of radionuclides from emplaced wastes (Bai et al., 2000; Bai et al., 1997; Bai et al., 1996; Bakhtar et al., 1993; and Chambre and Pigford, 1984).

The potential for damage of clayey barriers by ionizing radiation emitted by packaged radioactive waste is much higher at the canister/barrier interface than at radially distant locations. The radiation level at the surface of waste canisters has been estimated as $100 \mathrm{mrem} / \mathrm{hr}$ (Kehrman et al., 1987). It is conceivable that in the event of canister damage, radiation levels will be elevated at perforations if the waste is still in its highly radioactive state. The radiation component with the highest damage potential is gamma $(\gamma)$ radiation. Then, its effect would mostly be restricted to the first few millimeters of barrier thickness around the canister. Clayey barrier materials possess $\gamma$-attenuation characteristics which may reduce gamma levels near the barrier's external circumference to intensities that are incapable of generating activation-level dose rates. Data are unavailable on activation energies for radiolytic reactions in clays but related studies (Pusch et al., 1993) indicate that the exposure of montmorillonitic clay, saturated with weakly brackish water, to a $\gamma$-radiation dose of $3 \times 10^{7} \mathrm{~Gy}$ at $130{ }^{\circ} \mathrm{C}$ can cause the formation of minor amounts of quartz, $\mathrm{CaSO}_{4}$, and $\mathrm{MgSO}_{4}$. Calcite $\left(\mathrm{CaCO}_{3}\right)$ and feldspars which had been present as traces in the original clay, disappeared. In general, these changes are minor and were deemed insignificant with respect to overall barrier integrity by the investigators. In the case of water which may be present in the radiation field, the lifetime of excited molecules is below $10^{-11}$ seconds (Bugaenko et al., 1993), perhaps too short for the initiation and completion of chemical reactions that can lead to significant textural changes in the barrier. 
Under the expected high temperatures, at least during the initial radioactive decay phase of the waste, smectite crystals could dissolve in the inner annular section around the barrier if moisture requirements are met. Such moisture could be in the vapor phase and/or below saturation. Actually at emplacement, the barrier is expected to have very high density. Indeed experiments by Molecke and Torres (1983) show that $100 \%$ tamped bentonite (primarily Namontmorillonite) has a density of $1.29 \mathrm{~g} / \mathrm{cm}^{3}$, and data reviewed by Coulon et al. (1986) indicate that the natural moisture content of clay at a standard pressure of $100 \mathrm{MPa}$ ranges from 5.4 to $12.5 \%$. Essentially, the barrier clay will be undersaturated initially. Significant increases in moisture content must occur through ingress from the surrounding rock.

The thermodynamics and kinetics of barrier alteration processes in the repository will be significantly influenced by the rate of moisture increase. This parameter itself is influenced by the nature of coupling of the transport processes of both heat and moisture. Although ions needed to promote mineralogical transformations of barrier sections can be supplied through diffusion, increase in moisture by convection, under the high environmental pressure of the repository environment, should be regarded as a significant mechanism of elevation of the moisture content of the barrier to levels required for illitization of the Na-montmorillonite. Smectite (a family of clays that includes montmorillonite) illitization requires the availability of potassium ions $\left(\mathrm{K}^{+}\right)$. Feldspars and other minerals in the host rock can supply $\mathrm{K}^{+}$. The diffusion coefficients of ions through illite are generally higher than those through Na-montmorillonite) The implication is that the post-conversion transport situation for radionuclides through the barrier (if they are released from the canister) may be higher than would be expected if barrier alteration is negligible. Diffusion of ions can be enhanced by increase in temperature. In their investigations of $\mathrm{K}^{+}$ diffusion in silty loam, Schaff and Skogley (1982) found that an increase in temperature from 5 
to $30{ }^{\circ} \mathrm{C}$ increased $\mathrm{K}^{+}$diffusion between 1.6 and 1.7 times at each moisture level tested. $\mathrm{K}^{+}$ diffusion also increased with moisture content at constant temperature. Over the limited temperature range of $15-35^{\circ} \mathrm{C}$, Youssef et al. (1961) studied the effects of temperature on the index properties of clayey soils and developed temperature-based correction factors for liquid limit and viscosity. From their data, increase in temperature within the range they selected decreases both the liquid and plastic limits of soils. More recently, Kanno et al. (1995) have performed experiments that indicate that water diffusivity in compacted clayey soils (with a dry density of $1.8 \mathrm{~g} / \mathrm{cm}^{3}$ ) increases significantly with temperature in the range of $25-60{ }^{\circ} \mathrm{C}$. The coupling of heat and mass transport (both moisture and ions) in clayey barriers of repositories is a significant determinant of barrier alteration processes and the potential transport rates of radionuclides from canisters in the long run.

\section{THE MATHEMATICAL MODEL OF HEAT AND MOISTURE TRANSPORT}

A mathematical model is herein developed to describe the moisture fraction w, and temperature $\mathrm{T}$, in the region surrounding a cylindrical container of high-level nuclear waste buried deep underground. Immediately adjacent to the canister, is an engineered clay barrier. This engineered barrier is surrounded by a natural clay barrier.

Many of the essential mechanisms that determine the chemical environment near stored nuclear waste have already been identified and studied for short times. Moisture is generated by condensation and lost through evaporation and vaporization. Moisture is transported by hydrodynamic diffusion. At higher-pressure gradients, inertial effects might become important but not in the regime involved herein. Thermal energy is generated by the stored nuclear waste 
and the vaporization of water. Thermal energy is lost through condensation. Finally, thermal energy is transported through thermal diffusion in the barrier and the intergranular pore moisture. Macaskill et al. (2001) studied a similar chemical system in stored bagasse in a different geometric configuration over shorter durations. In this analysis, the moisture fraction w, is a dimensionless quantity equal to the ratio of volume of liquid water to total volume; its value ranges from a minimum of 0 for a completely dehydrated region to a maximum of $\mathrm{n}$, the porosity of the matrix. We make the following assumptions in developing the model.

- The air pressure in the porous matrix is constant. This model is multiphase, but all regions not occupied by the matrix or by liquid water are assumed to be occupied by air. The vapor pressure in the air is determined such that it is in equilibrium with the far field moisture content at the far field temperature. Any excess water vapor generated by evaporation is assumed to be transported out of the barrier region.

- The water, air and porous matrix are in thermal equilibrium. This assumption is justified by the fact that the heat transport times between clay, air and water are on the order of seconds and minutes, whereas the hydrodynamic transport of moisture in clay requires days, months, and even years.

- There are no open fractures in either the engineered barrier or the host rock because the engineered barrier will swell and close any fractures. Fractures in the host rock will be largely closed because of the very high overburden pressure that characterizes deep burial environments.

- Mineralogical and chemical reactions within the barrier do not significantly affect the moisture and heat transport. Barrier alteration would result in a more complex coupled system of equations that will be treated in future work. 
- The solution is axisymmetric: that is, $w$ and $T$ vary only with time $t$ and with radial distance $r$ from the axis of the waste canister. The region of interest is a thick vertically uniform, annular pancake surrounding the storage cylinder as described by Carr and Basham (1983). The measurements of Kanno et. al. (1995) support this assumption. This is not essential for the formulation of the basic model, but it permits a simple implementation of the model in a cylindrical geometry.

Conservation of thermal energy and conservation of water mass provide the two equations needed to solve for the two unknown quantities $T$ and $w$. The relevant processes for conservation of thermal energy density are thermal diffusion via Fourier's law, evaporation and condensation:

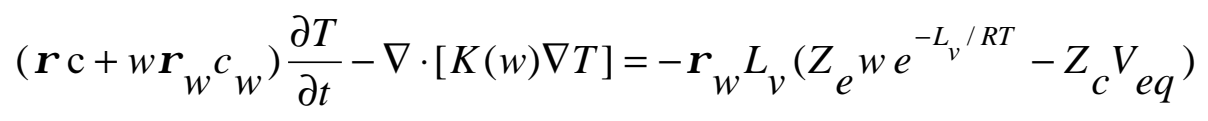

where $\rho$ is the density of clay, $\rho_{w}$ is the moisture density, $\mathrm{c}$ is the heat capacity of the barrier, $\mathrm{c}$ is the heat capacity of water, $\mathrm{L}_{v}$ is the latent heat of vaporization of the water, $\mathrm{Z}_{e}$ is the rate constant associated with the Arrhenius model for evaporation, $\mathrm{R}$ is the universal gas constant, $\mathrm{Z}_{c}$ is the condensation rate and $\mathrm{V}_{\text {eq }}$ the equilibrium vapor pressure in the porous matrix which is assumed to be constant. The units of measurement of these parameters are Appendix I. The thermal diffusivity $\mathrm{K}(w)$ is easily determined by the components already in place

$$
K(w)=k_{b}+w k_{w}
$$

where $\mathrm{k}_{\mathrm{b}}$ is the thermal conductivity of the barrier material and $\mathrm{k}_{w}$ is the thermal conductivity of water. The equilibrium vapor content $\mathrm{V}_{\mathrm{eq}}$ is determined from the far-field temperature $\left(\mathrm{T}_{0}\right)$ and moisture content $\left(w_{0}\right)$ so that condensation rate is equal to the evaporation rate. 


$$
V_{e q}=\frac{Z_{e} w_{0} e^{-L_{v} / R T_{0}}}{Z_{c}}
$$

It is reasonable to neglect advection of thermal energy with the fluid flow because the fluid flux is much smaller than the thermal flux. Then, the porous matrix and fluid are in thermal equilibrium. The conductivity of air is neglected, as it is very small. The conductivity attributed to ambient vapor is disregarded because $\mathrm{V}_{e q}$ under typical conditions, is on the order of one part in $10^{4}$ and has no measurable effect relative to the conductivity of the barrier.

The relevant processes for conservation of water (moisture and vapor) are diffusion (driven by the moisture potential for unsaturated soils) and evaporation/vaporization.

$$
\frac{\partial w}{\partial t}-\nabla \cdot[D(w) \nabla w]=-Z_{e} w e^{-L_{v} / R T}+Z_{c} V_{e q}
$$

The hydraulic diffusivity $\mathrm{D}(w)$ incorporates a number of effects known in soil physics such as wetting and sorptivity. For this practical implementation, the diffusivity $\mathrm{D}(w)$ is fitted to measured data on Yolo light clay provided by Philip (1969 and 1996).

$$
D(w)=10^{-d(w)} \frac{m^{2}}{\mathrm{sec}}
$$

where

$$
d(w)= \begin{cases}8.3+15000(w-0.03)^{2}, & w<0.03 \\ 8.3-25171.7(w-0.1)(w-0.03)^{2}, & w \in[0.03,0.080825) \\ 7.0+25(w-0.4)^{2}, & w \in[0.080825,0.4) \\ 7.0+\frac{(w-0.4)^{2}}{4(w-0.3)(w-0.5)}, & w \in[0.4,0.5)\end{cases}
$$

The results of the fit are shown in Figure 1. Hydraulic diffusivity curves like the one in Figure 1 have not been measured for many materials although the general behavior of the curve is somewhat universal for different clays. 
The remainder of this paper is dedicated to the specific problem of quantifying the spatiotemporal location of the vaporization front in a cylindrical waste canister embedded in a clay barrier. One would expect any solution to equations (1) and (4) with axisymmetric boundary and initial conditions to have axisymmetric solutions. The basic geometry is shown in Figure 2.

To supplement equations (1) and (4), it is necessary to determine the appropriate boundary conditions. The waste canister occupies the space $0=r=R_{0}$, the engineered clay barrier occupies the space $R_{0}<r=R_{1}$, and the host rock occupies the space $R_{1}<r=R_{2}$. Thus, the domain for the solution of the model equations is $\mathrm{R}_{0}=\mathrm{r}=\mathrm{R}_{2}$. The region occupied by the waste canister is treated as a "black box" save for a specified thermal flux $H_{c}$ from the edge at $\mathrm{R}_{0}$, and it is assumed that the moisture in the clay barrier cannot penetrate the canister. Furthermore, it is assumed that the temperature and moisture fraction in the region surrounding the host rock have the constant values $T_{0}$ and $w_{0}$, respectively. Thus, the boundary conditions are:

$$
\begin{gathered}
\frac{\partial T}{\partial r}\left(R_{0}, t\right)=-\frac{H_{\mathrm{c}} \mathrm{e}^{-? \mathrm{t}}}{2 \mathrm{p} \mathrm{R}_{0}\left(k_{b}+w k_{w}\right)} \\
\frac{\partial w}{\partial r}\left(R_{0}, t\right)=0 \\
T\left(R_{2}, t\right)=T_{0} \\
w\left(R_{2}, t\right)=w_{0}
\end{gathered}
$$

For initial conditions, it can be assumed that the temperature and moisture are everywhere equal to the ambient values:

$$
\begin{aligned}
& T(r, 0)=T_{0} \\
& w(r, 0)=w_{0}
\end{aligned}
$$

Finally, the thermal flux and the hydraulic flux are continuous at the interface between the 
engineered barrier and the host rock. With a cylindrical domain, equations (1) and (4) become

$$
\begin{gathered}
\left(\rho \mathrm{c}+w \rho_{w} c_{w}\right) \frac{\partial T}{\partial t}=\frac{1}{r} \frac{\partial}{\partial r}\left[r K(w) \frac{\partial T}{\partial r}\right]-H_{N}\left(T-T_{0}\right)-\rho_{w} L_{v}\left(Z_{e} w e^{-L_{v} / R T}-Z_{c} V_{e q}\right) \\
\frac{\partial w}{\partial t}=\frac{1}{r} \frac{\partial}{\partial r}\left[r D(w) \frac{\partial w}{\partial r}\right]-Z_{e} w e^{-L_{v} / R T}-Z_{c} V_{e q}
\end{gathered}
$$

A full three-dimensional model would include a term for the vertical diffusion of heat in equation (13) of the form $D(w) \partial^{2} T / \partial z^{2}$ plus far-field boundary conditions at the surface, but noting that the solution is essentially axisymmetric within a radial distance of many cylinder radii (Kanno et al., 1995), vertical heat diffusion can be replaced with a Newton cooling term The Newton cooling term $H_{N}\left(T-T_{0}\right)$ is a modification specific to the axisymmetric problem used to address physical and mathematical considerations. Physically, it is defensible to expect thermal energy to interact with surrounding material above and below the storage layer. Mathematically, there must be some form of heat loss to counteract the thermal energy input. In fact, if moisture is absent from the system and the barrier has uniform thermal properties throughout, there is an exact, steady solution for temperature.

$$
\begin{aligned}
& T=T_{0}-\frac{H_{c}}{2 \mathrm{p} R_{0} k_{b}} \sqrt{\frac{k_{b}}{H_{N}}}\left[I_{1}\left(\sqrt{\frac{H_{N}}{k_{b}}} R_{0}\right)+\frac{I_{0}\left(\sqrt{H_{N} / k_{b}} R_{1}\right)}{K_{0}\left(\sqrt{H_{N} / k_{b}} R_{1}\right)} K_{1}\left(\sqrt{H_{N} / k_{b}} R 0\right)\right]^{-1} x \\
& {\left[I_{0}\left(\sqrt{\frac{H_{N}}{k_{b}}} r\right)-\frac{I_{0}\left(\sqrt{H_{N} / k_{b}} R_{1}\right)}{K_{0}\left(\sqrt{H_{N} / k_{b}} R_{1}\right)} K_{0}\left(\sqrt{H_{N} / k_{b}} r\right)\right] }
\end{aligned}
$$

where $I_{\mathrm{m}}$ is the modified Bessel function of the first kind having an order $m$, and $K_{\mathrm{m}}$ is the modified Bessel Function of the second kind of order $m$. This solution has a number of important uses. First, it can provide a means for calibrating $H_{N}$ if there is available information on such 
parameters as the thermal output of the waste canister, its surface temperature and the equilibrium temperature in the far field. Second, it provides a means of testing numerical schemes by providing a reference solution for the decoupled problem.

\section{NUMERICAL SOLUTION ALGORITHM}

Equations (13) and (14) are solved numerically using the method of lines. The method of lines is arguably one of the simplest schemes for attacking parabolic partial differential equations (PDEs). Essentially, the spatial domain is discretized, and the resulting coupled system of ordinary differential equations (ODEs) are solved using standard ODE solvers. In this case, the parabolic system is discretized to second order using the method outlined by Skeel and Berzins (1990) and implemented in MATLAB. In Figure 3, the numerical approximation is shown to be in extremely close agreement with the exact solution (equation 15) with sample parameter constants.

For the remainder of this report, a uniform mesh of 0.1 meters is used from the waste canister (with a 1 meter diameter) out to a radius of 2 meters. From 2 meters to 3 meters, a coarser mesh of 0.25 meters is used. With this geometry, the cooling coefficient $\mathrm{HN}=6.7 \times 10^{-2}$ is chosen so that with typical waste thermal outputs, the canister exterior reaches a temperature of roughly 250 degrees $\mathrm{C}$ which is the upper regime of temperatures expected in repositories (with a factor of safety). Time integration is performed using a variable accuracy stiff solver with relative error tolerances set to be less than one part in $10^{4}$.

\section{SIMULATIONS}


This section presents a sample computation using a variety of likely parameter values. These values are tabulated in Appendix I. It is assumed that the porous matrix is almost saturated at $R_{2}$ so that $w_{0}=0.40$. Initially, the temperature field is uniformly $T_{0}$ and the moisture content is $w_{0}$. Half-lives for radionuclides vary from 100 years to 10,000 years. When half-lives for radionuclides exceed the warm-up period, there is a separation of time-scales so that advance of the front is independent of the half-life and the recession of the front scales proportionally to the half-life. In Figure 4, it can be observed that for shorter lives (a), the decay timescale is coupled to the formation timescale so that the vaporization front advance is retarded compared to storage of materials with longer half-lives. For longer half-lives (b), the warm-up timescale and the decay timescale are sufficiently separated such that the processes are decoupled. In Figure 5, it is observed that the vaporization front forms within a century of introducing the waste. Since the half-life is an order of magnitude larger than the formation time, the decay of the stored waste will not have any significant impact on the formation or location of the front. Also, the relaxation time of the front will scale linearly with $1 / \lambda$ as one would expect. The same results are observed for smaller values of $\lambda$. The simulation domain is longer than that shown $(\mathrm{r} 2=50)$. Thus, relaxation to equilibrium in the far field is fully established well beyond $r=1.5$. Also a quasisteady vaporization front forms and propagates outward over the course several decades.

Perhaps the most important feature of these solutions is the presence of moisture behind the vaporization front. Thus, it is observable that between the waste and the vaporization front, there is a region where the temperature and moisture content may be high enough to support mineralogical transformations of the Na-smectite that is used as the primary constituent of the clay barrier. The transport of moisture into the porous matrix is computed from the moisture 
gradients in Figure 6. As the vaporization front moves outward during the warm-up period, the moisture transport profile moves outward as expected. Similar behavior is observed as the core decays and the front moves back toward the waste canister.

\section{CONCLUSIONS}

In this paper, a simple mathematical model that describes the temperature and moisture fraction in the region surrounding a nuclear waste canister has been developed and applied to a hypothetical case. The model incorporates thermal diffusion, diffusion of water (driven by the moisture potential for unsaturated soils), vaporization, and condensation. The partial differential equations that constitute the model are solved numerically using the method of lines. The results indicate that a vaporization front forms and initially moves away from the waste canister, reaching a location at which the effects of vaporization and inward diffusion of water are in balance. As the radioactive waste cools, the front slowly moves back toward the waste canister. The evolution of the front is relatively insensitive to changes in the half-life of the waste material and the permeability of the barrier material. A future paper will address the issue of possible chemical degradation of the barrier material through processes such as illitization.

\section{APPENDIX I. NOTATIONS}

The following physical constants are used in the computations presented in this paper. Some have been obtained from standard tables. Others have been determined from studies such as those of Carr and Basham (1983) and Kanno et al. (1995). All numerical values are given in MKS units. 


$$
\begin{aligned}
& \mathrm{R}=\text { universal gas constant }(8.31 \mathrm{~J} / \mathrm{kg} \mathrm{K}) \\
& \mathrm{H}_{\mathrm{c}} \quad=\text { thermal output of nuclear waste }\left(2.2 \times 10^{3} \mathrm{~W}\right) \\
& c=\text { heat capacity of barrier }\left(10^{5} \mathrm{~J} / \mathrm{mol} \mathrm{K}\right) \\
& c_{\mathrm{w}}=\text { heat capacity of water }(4.1819 \times 103 \mathrm{~J} / \mathrm{kg} \mathrm{K}) \\
& k_{\mathrm{b}}=\text { thermal conductivity of the barrier }(0.33 \mathrm{~W} / \mathrm{m} \mathrm{K}) \\
& k w=\text { thermal conductivity of water }(0.67 \mathrm{~W} / \mathrm{m} \mathrm{K}) \\
& L_{\mathrm{v}}=\text { heat of vaporization of water }\left(4.07 \times 10^{4} \mathrm{~J} / \mathrm{kg}\right) \\
& R_{0} \quad=\quad \text { radius of storage vessel }(0.5 \mathrm{~m}) \\
& T_{0} \quad=\text { ambient temperature underground }\left(20{ }^{\circ} \mathrm{C}\right) \\
& w \quad=\text { moisture fraction }([0,0.5] \text { for Yolo light clay }) \\
& \rho=\text { density of porous substance }\left(1.6 \times 10^{3} \mathrm{~kg} / \mathrm{m}^{3}\right) \\
& \rho_{w} \quad=\text { density of water }\left(10^{3} \mathrm{~kg} / \mathrm{m}^{3}\right) \\
& Z_{\mathrm{e}} \quad=\text { Arrhenius evaporation rate }\left(3.41 \times 10^{4} \mathrm{sec}^{-1}\right) \\
& Z_{\mathrm{c}}=\text { condensation rate }\left(4.7 \mathrm{sec}^{-1}\right)
\end{aligned}
$$

\section{APPENDIX II. REFERENCES}

Bai, M. Elsworth, D., Inyang, H. I. and Roegiers, J. C. (1997). “Modeling contaminant migration with linear sorption in strongly heterogeneous media". Journal of Environmental Engineering, 123, No. 11, pp. 1116-1124.

Bai, M., Elsworth, D., Inyang, H. I. And Roegiers, J. C. (1997). "Modeling contaminant migration with linear sorption in strongly heterogeneous media". Journal of Environmental Engineering, ASCE, 123 (11), 1116-1124.

Bai, M., Mo, H., Inyang, H. I., Abousleiman, Y. and Roegiers, J. C. 2000. “Analysis of capture 
zone and pump-and-treat method in fractured rocks. ASCE Special Publication on Remediation in Rock Masses, pp. 42-55.

Bai, M., Roegiers, J. C. and Inyang, H. I. (1996). "Contaminant transport in non-isothermal fractured media”... Journal of Environmental Engineering, ASCE, 122 (5), 416-423.

Bakhtar, K., Summers, D. A. and Inyang, H. I. (1993). “A note on physical modeling approach for assessment of excavation techniques. Proceedings of the 1993 International HighLevel Radioactive Waste Management Conference, Las Vegas, Nevada, pp. 293-299.

Bugaenko, L. T., Kuzmin, M. G. and Polak, L. S. (1993). "High Energy Chemistry". Ellis Horwood and Prentice-Hall Publishers, New York, U.S.A.

Carr, John A. and Bashan, S. J. (1983). "Waste package conceptual designs for salt". In Roy G Post, editor, Waste Management '83: Proceedings of the Symposium on waste Management, Vol. II, pages 17-20, 1983.

Chambre, P. L. and Pigford, T. H. (1984). "Prediction of waste performance in a geologic repository". Proceedings of the Materials Research Society Symposium on Scientific Basis for Nuclear Waste Management VII, Boston, MA, pp. 985-1008.

Chen, J., Anandarajah, A. and Inyang, H. I. (2000). "Pore fluid properties and compressibility of kaolinite". Journal of Geotechnical and Geoenvironmental Engineering, ASCE ，798807.

Coulon, H., Lajudie, A., Debrabant, P., Atabek, R., Jorda, M. and Andre-Jehan, R. (1986). "Choice of French clays as engineered barrier components for waste disposal". Proceedings of the Materials Research Society Symposium on Scientific Basis for Nuclear Waste Management X, Boston, MA, pp. 813-824.

Daniels, J. L. and Inyang, H. I. (2002). "Durability of Boston Blue Clay in waste containment 
applications." Journal of Materials in Civil Engineering, ASCE, in press.

Daniels, J.L., Chien, C.C., Ogunro, V.O. and Inyang, H.I. (2000). "A comparative analysis of contaminant migration models using barrier material data." Journal of Soil and Sediment Contamination 9(5), 487-501.

Inyang, H. I., Daniels, J. L. and Chien, C.C. (2000a). "Methods of analysis of contaminant migration in barrier materials". In: Remediation of Hazardous Waste Contaminated Soils, $2^{\text {nd }}$ Edition, editors:D. L. Wise, D. J. Trantolo, W. J. Cichon, H. I. Inyang and U. Stottmeister. Marcell Dekker Publishing Company, New York, pp. 63-82.

Inyang, H.I., Iskandar, A., and Parikh, J. M. (1997). "Physico-chemical interactions in waste containment barriers. Encyclopedia of Environmental Analysis and Remediation, 2, John Wiley and Sons, pp. 1158-1165.

Kanno, T., Fujita, T., Takeuchi, S., Ishikawa, H., Hara, K. and Nakano, M. (1995). "Coupled thermo-hydro-mechanical modelling of bentonite buffer material". Proceedings of the International Workshop on Hydro-thermo-Mechanics of Engineered Clay barriers and geological barriers, Montreal, Canada, July 5-7 1995. McGill University, pp.1-50..

Macaskill, C., Sexton, M. J. and Gray, B. F. (2001) "A reaction-diffusion model of stored bagasse". ANZIAM Journal, 43:13-34, July 2001.

Molecke, M. A. and Torres, T. M. (1983). "The waste package materials field test in S.E. New Mexico salt.” Proc. Materials Research Society Symposium on Scientific Basis for Nuclear Management VII, Boston, MA, pp. 69-76.

Philip, J. R. (1969). "Theory of infiltration”. In Ven Te Chow, editor, Advances in Hydroscience, volume 5, pages 215-296. Academic Press, 1969.

Philip, J. R. (1996). "Mathematical physics of infiltration on at and sloping topography". In 
Mary Fanett Wheeler, editor, Environmental studies: Mathematical, Computational, and Statistical Analysis, volume 79, pages 327-349, New York, 1996. IMA, Springer-Verlag.

Pusch, R., Karnland, O., Lajudie, A. and Decarreau, A. (1993). "MX 80 clay exposed to high temperatures and gamma radiation". SKB Technical Report, TR 93-03, SKB, Stockholm, Sweden.

Schaff, B. E. and Skogley, E. O. (1982). "Diffusion of potassium, calcium and magnesium in Bozeman silt loam as influenced by temperature and moisture”. Soil Science Society of America Journal, 46, pp. 521-524.

Seitz, Roger R., Sagar, Budhi and Davis, Jerry D. (????). "Numerical modeling of radionuclide transport through repository seals". pages 637-644.

Shi, B., Murakami, Y., Wu, Z., Chen, J. and Inyang, H. I. (1999a). "Monitoring internal failure evolution in soils using computerized x-ray tomography (CT)". Engineering Geology, 54 (3-4), 321-328.

Skeel, R. D. and Berzins, M.. (1990) "A method for the spatial discretization of parabolic equations in one space variable”. SIAM J. Sci. Stat. Comput., 11:1-32, 1990.

Youssef, M. S., Sabry, A. and Ramli, A. H. E. (1961). "Temperature changes and their effects on some physical properties of soils". Proceedints of the Fifth International Conference on Soil Mechanics and Foundation Engineering, Paris, France, pp. 419-421. 


\section{List of Figures}

Fig. 1. Hydraulic conductivity fit for Philips’ Yolo light clay data (Philip, 1969 and 1996).

Fig. 2. Schematic diagram of the storage site. It is assumed that the moisture content and temperature are at equilibrium above and below the storage layer.

Fig. 3. Graph of an exact solution for the steady state decoupled temperature distribution superimposed on computed results after letting the simulation approach equilibrium. (Computations for $H_{N}=0.002, H_{c}=5000, k_{b}=1, R_{0}=0.5, R_{1}=50$, and $T_{0}=20$.

Fig. 4. Computations of the vaporization front for (a) $\lambda=0.01$ year $^{-1}$ and (b) $\lambda=0.001$ year $^{-1}$.

Fig. 5. Prediction of vaporization front in Yolo light clay after core insertion with $\lambda=0.001$ year $^{-1}$. The temperature is indicated with solid lines and the dimensionless moisture content with dashed lines.

Fig. 6. Computations of moisture flux in the porous matrix for (a) $\lambda=0.01$ year $^{-1}$ and (b) $\lambda=0.001$ year $^{-1}$. 
Hydraulic diffusivity fit

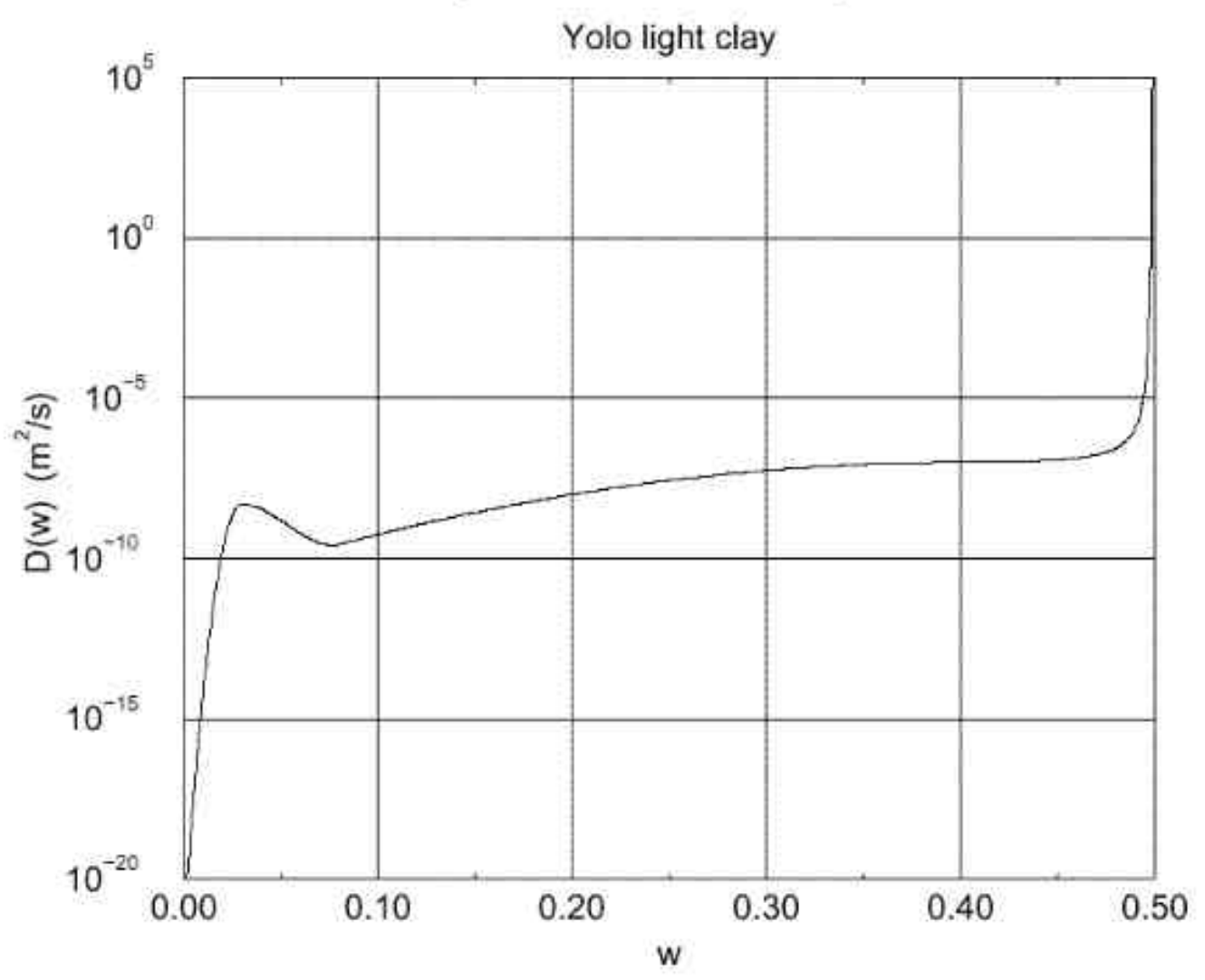

Fig. 1 


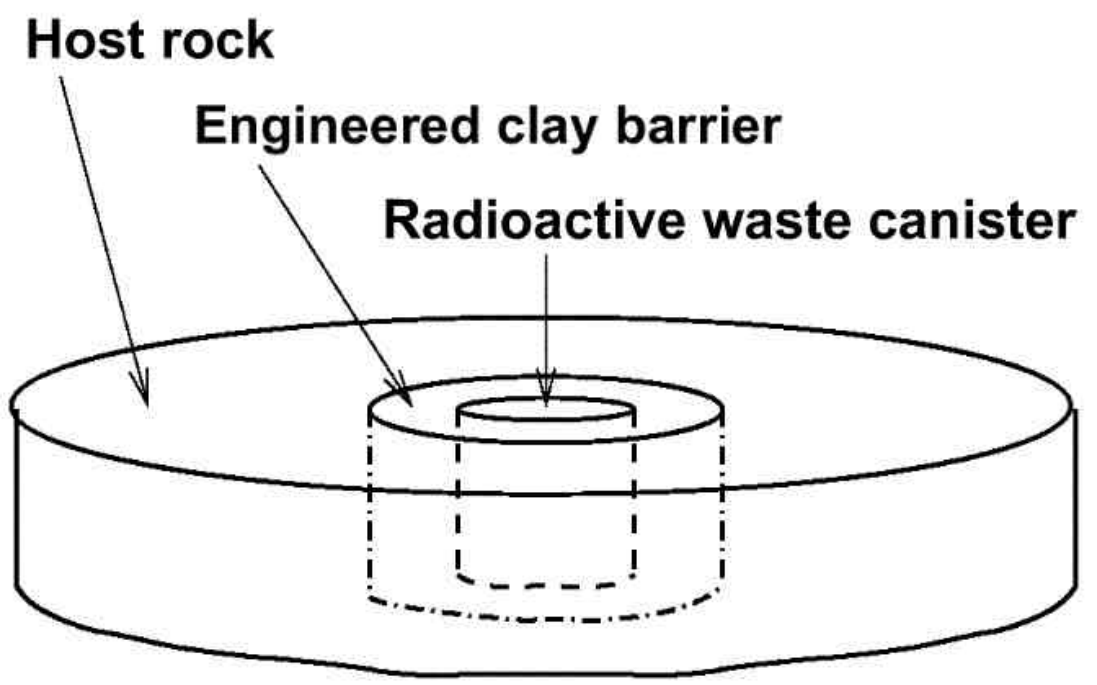

Fig. 2 


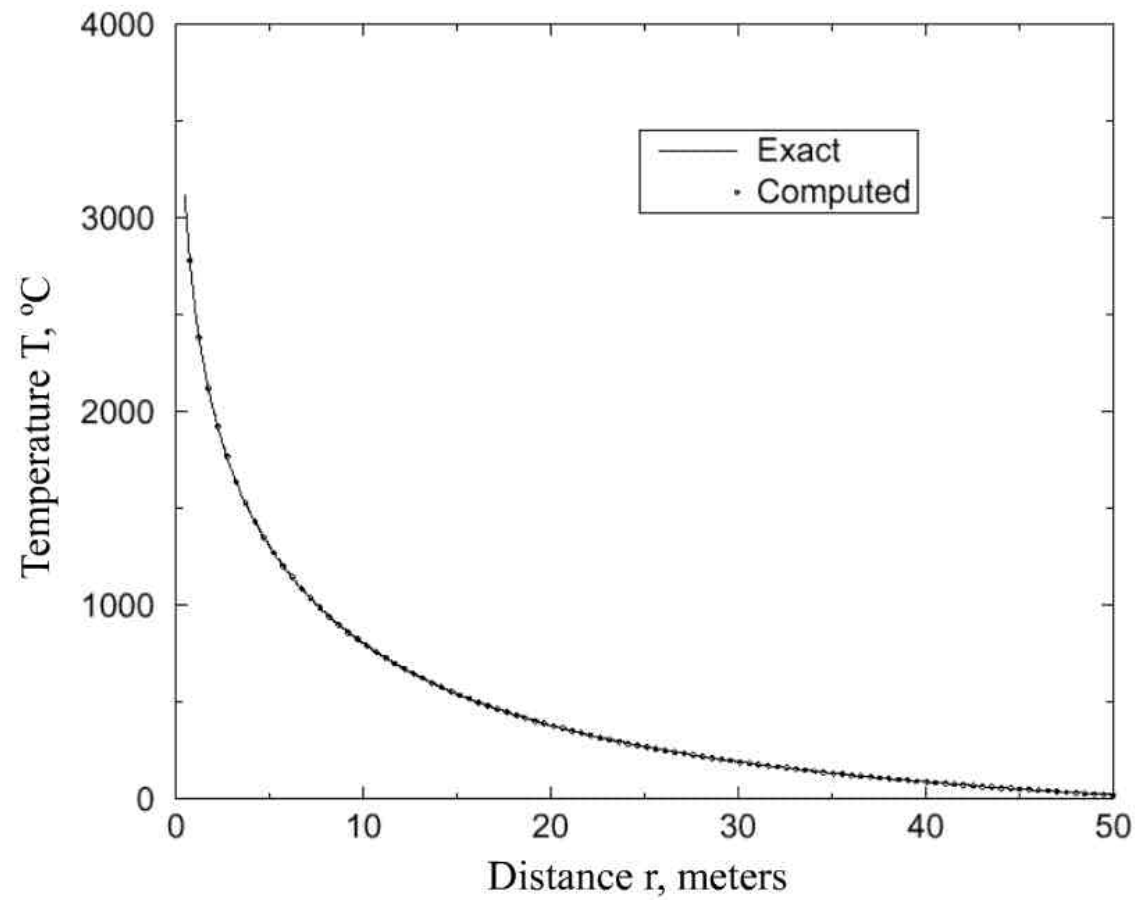

Fig. 3 
(a)

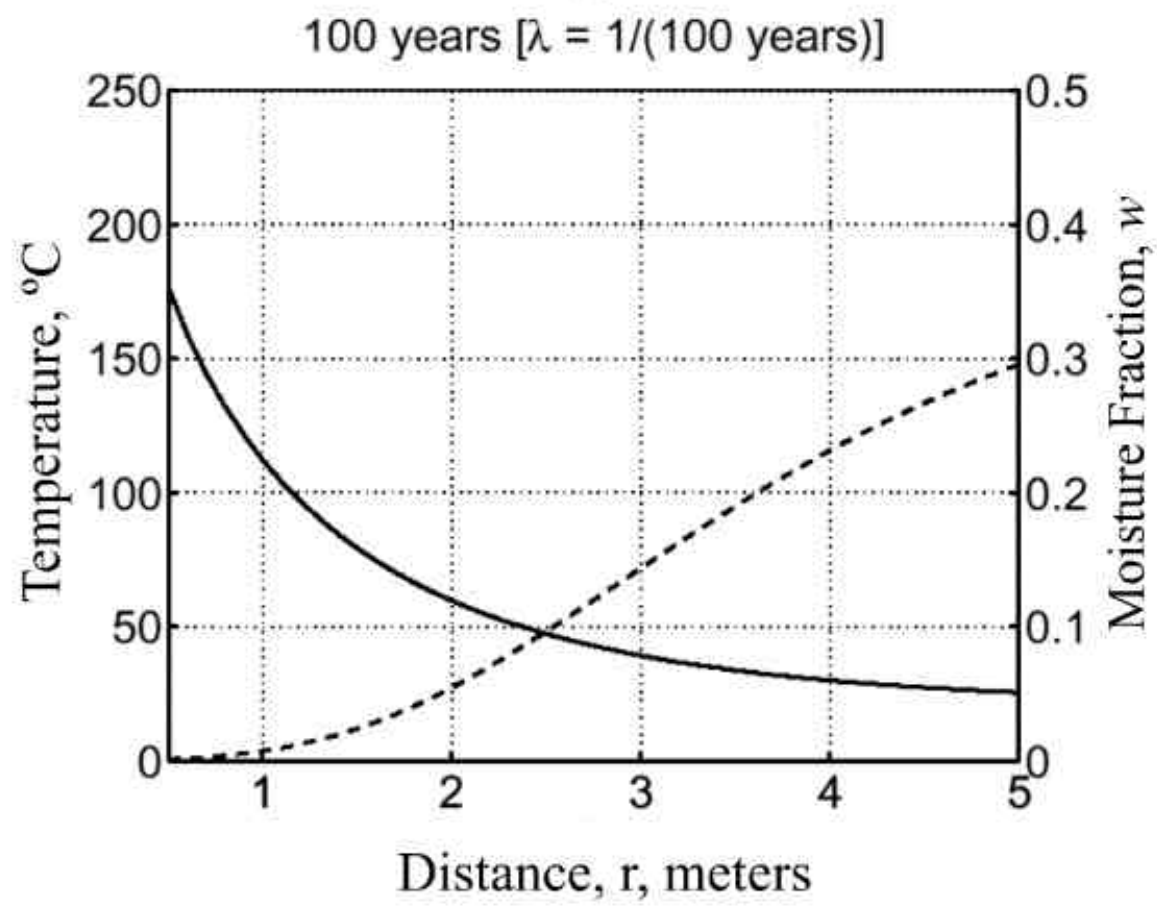

(b)

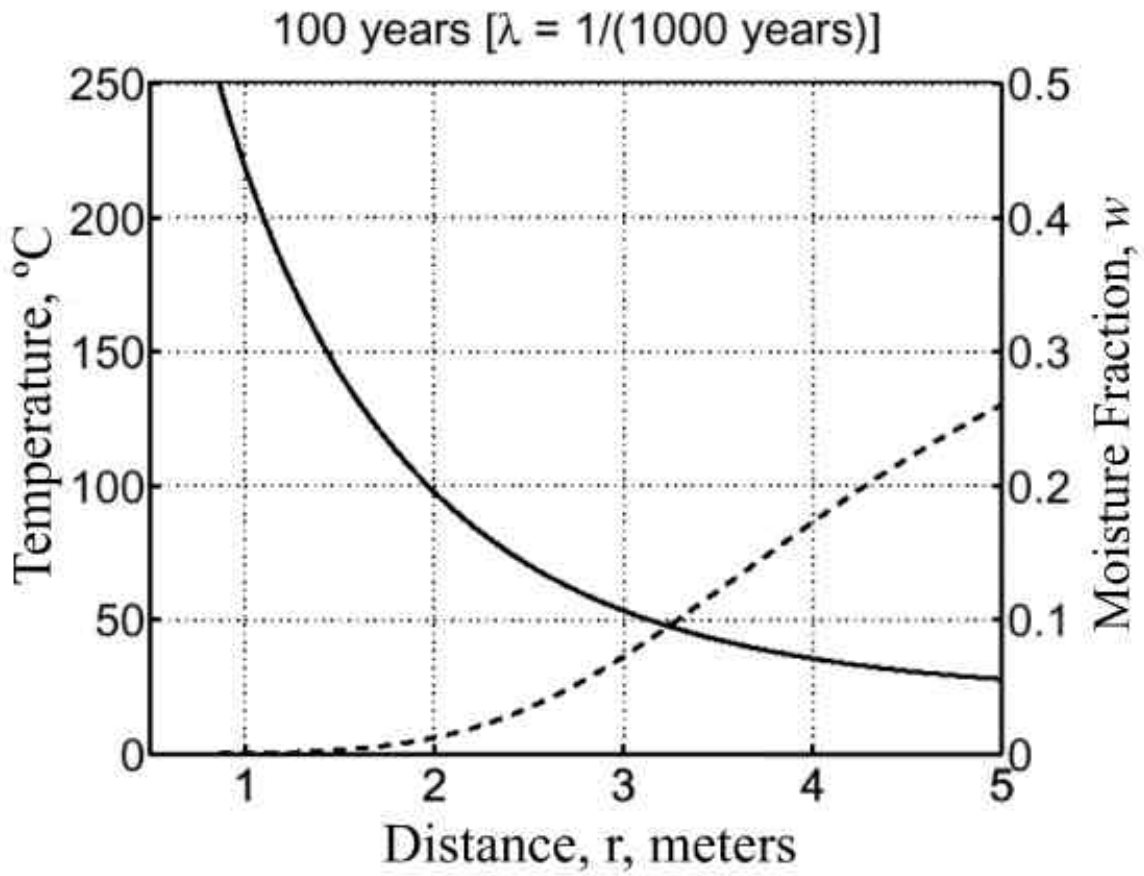

Fig. 4. 

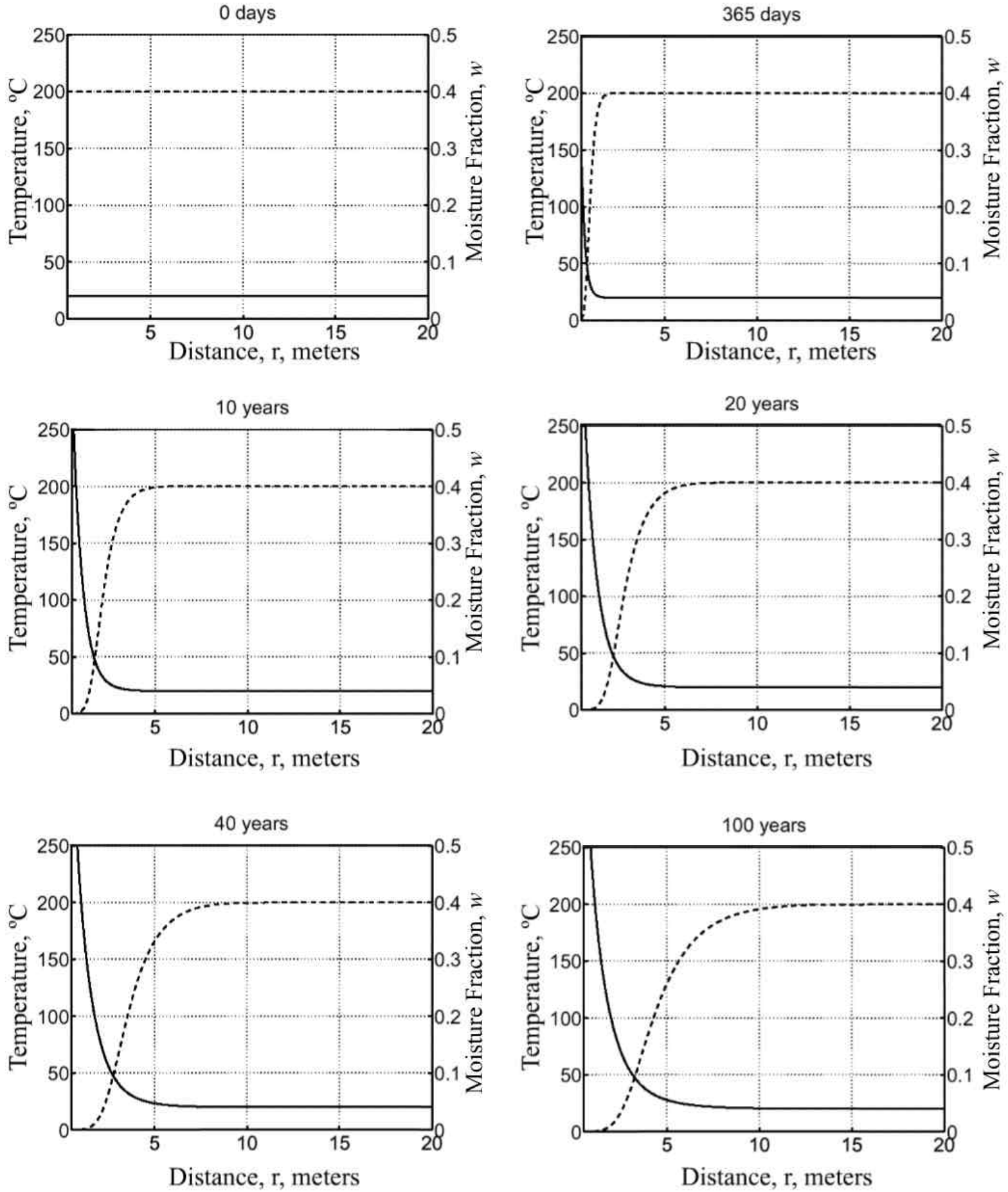

Fig. 5. 
(a)

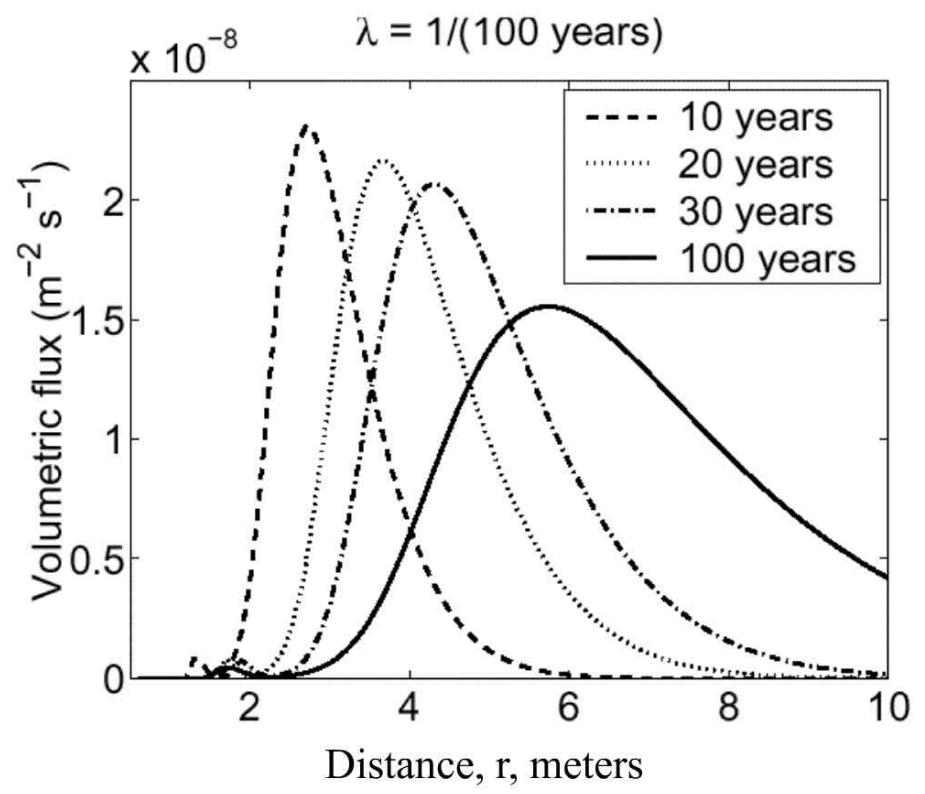

(b)

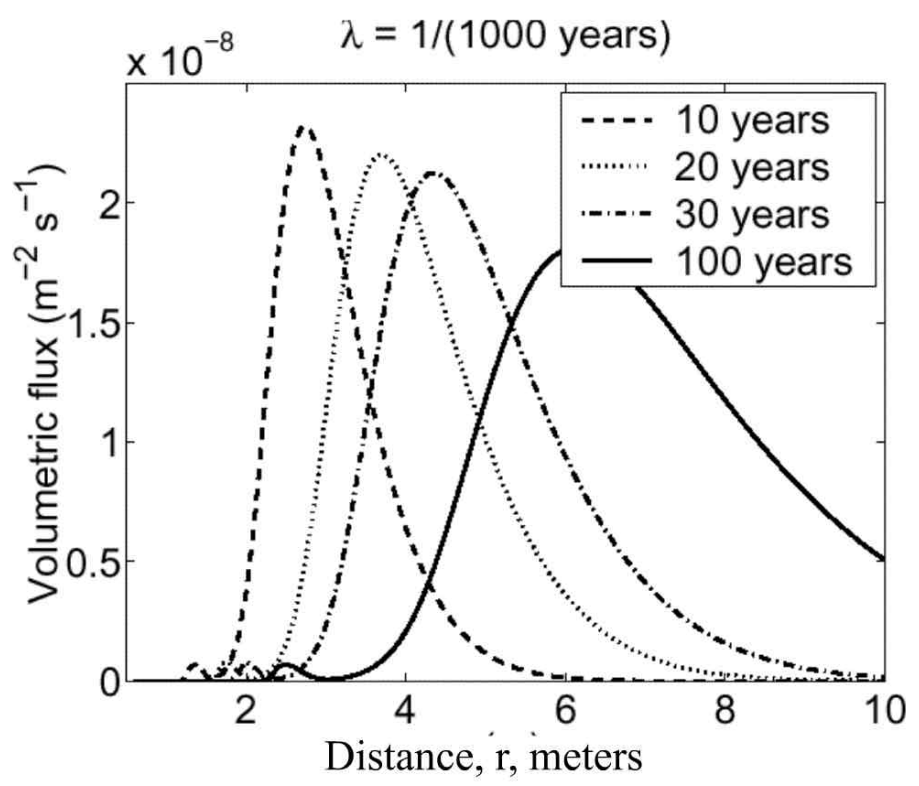

Fig. 6. 